\title{
PERAMALAN PENJUALAN KARTU DAN VOUCHER INTERNET MENGGUNAKAN METODE SINGLE MOVING AVERAGE (STUDI KASUS: TOKO KARYA PULSA)
}

Forecasting Internet Card and Voucher Sales Using The Single Moving Average Method (Case Study: Toko Karya Pulsa)

\author{
Nurmala Agustin Pertiwi ${ }^{1}$, Ratih Puspasari ${ }^{2}$ \\ ${ }^{1}$ Jurusan Sistem Informasi Universitas Potensi Utama \\ ${ }^{2}$ Dosen Jurusan Sistem Informasi Universitas Potensi Utama \\ ${ }^{1,2}$ Universitas Potensi Utama, K.L. Yos Sudarso KM 6,5 No. 3A Tj. Mulia-Medan \\ Email : agustinurmalaa@gmail.com ${ }^{1}$, ratih@potensi-utama.ac.id ${ }^{2}$
}

\section{ABSTRAK}

Toko Karya Pulsa ialah salah satu toko yang menjual pulsa, paket data, aksesoris handphone, dan lain-lain yang terletak di Jalan Karya No. 145. Toko Karya Pulsa telah berdiri sejak April 2015 silam dan masih terus berdiri serta beroperasi hingga detik ini. Dalam perjalanan bisnisnya, Toko Karya Pulsa juga mengalami ketidakpastian penjualan dimana suatu ketika penjualan cukup banyak dan dilain waktu bisa lebih sedikit. Ketidakpastian penjualan ini, khususnya penjualan kartu perdana internet dan voucher paket data menyebabkan dampak berupa kerugian pada Toko Karya Pulsa karena kedua jenis produk ini memiliki masa aktif alias expired. Jika sampai tenggang waktu tertentu, maka kuota internet yang ada pada voucher dan kartu perdana akan hangus. Pemilik Toko Karya Pulsa terkadang melakukan kesalahan saat menentukan stok barang sehingga terjadi terpaksa mengobral barang agar barang bisa terjual sebelum expired dan terkadang karena kekurangan stok, beberapa permintaan tak dapat terpenuhi. Demi meminimalisir terjadinya hal yang sama lebih sering, dibutuhkan sebuah aplikasi peramalan yang dapat dijadikan bahan acuan dalam mengantisipasi stok dengan lebih baik. Adapun metode peramalan yang digunakan adalah metode Single Moving Average, sebuah metode yang cocok digunakan untuk meramalkan sesuatu yang tidak musiman. Adapun hasilnya menunjukkan bahwa sebagian besar jumlah ramalan tidak terpaut terlalu jauh dengan hasil sebenarnya.

Kata Kunci : Penjualan, Peramalan, Single Moving Average

\section{ABSTRACT}

Karya Pulsa Store is one of the stores that sells pulses, data packages, handphone accessories, and others located on Jalan Karya No. 145. The Karya Pulsa Store has stood since April 2015 submission and still continues to stand as well as operate until this second. In the course of his business, the Karya Pulsa Store also experiences sales uncertainty where a time when sales are sufficiently large and other times can be less. This uncertainty of sales, particularly the sale of internet premiere cards and data packet vouchers caused an impact in the form of a loss on Karya Pulsa Store as both types of these products had an active period of expired aliases. If it is up to a certain grace time, then the existing internet quota on the voucher and the inaugural card will be scorched. Owners of the Karya Pulsa Store sometimes make mistakes when determining stocks so that occurring forced to reprimand goods in order to sell goods before expired and sometimes due to shortages in stock, some demands are unfulfilled. In the interest of minimizing the occurrence of the same more often, it takes an app for forecasting that can be used as a reference material in better anticipation of stock. As for the forecasting method used is the Single Moving Average method, a suitable method is used to foresee something that is not seasonal. As for the results showed that most of the number of predictions was not adrift too far with the actual result.

Keywords: Sales, Forecasting, Single Moving Average 


\section{PENDAHULUAN}

Toko Karya Pulsa merupakan sebuah toko yang menjual berbagai macam produk seperti kartu perdana internet, voucher paket data, pulsa, inject paket data, voucher pulsa, aksesoris smartphone, dan lain-lain yang terletak di Jl. Karya No. 195, Karang Berombak. Toko Karya Pulsa telah beroperasi sejak 15 April 2014 silam dan masih terus beroperasi hingga saat ini. Awalnya Toko Karya Pulsa belum menyediakan voucher paket data, namun sejak pemerintah mulai memberlakukan aturan pendaftaran kartu perdana internet harus menggunakan data kependudukan yang valid maka disediakan pula voucher paket data demi memudahkan para pelanggan untuk memperoleh paket data tanpa harus berkali-kali melakukan pendaftaran kartu perdana internet.

Sejak pertama berdiri hingga saat ini penjualan di Toko Karya Pulsa bersifat tidak tetap, terkadang lebih banyak Xl, terkadang lebih banyak Axis, terkadang lebih banyak Tri. Ketidakpastian penjualan ini menyebabkan pemilik sering ragu dalam menentukan jumlah stok dari masing-masing kartu perdana internet dan voucher paket data mengingat kartu perdana internet dan voucher paket data memiliki masa aktif, dimana ketika masa aktif kartu perdana internet dan voucher paket data telah berakhir, maka kuota internet yang ada didalamnya akan hangus alias tidak dapat digunakan lagi. Hal ini tentu saja mengakibatkan kerugian. Pemilik Toko Karya Pulsa bahkan masih beberapa kali melakukan kesalahan dalam menentukan stok kartu perdana internet yang menyebabkan kartu perdana internet tersebut harus diobral dengan harga dibawah modal.

Penerapan peramalan dapat menjadi suatu langkah yang dapat diambil untuk mengurangi ketidakpastian yang terjadi selama ini. Peramalan merupakan salah satu aktivitas yang dapat menunjang keberhasilan suatu organisasi dan perusahaan dalam memperoleh keuntungan maksimal. Dengan melakukan peramalan, perusahaan dapat mengantisipasi ketersediaan stok dengan lebih baik, tidak terlalu banyak yang mengakibatkan biaya penyimpanan lebih banyak, dan tidak terlalu sedikit yang mengakibatkan tidak mampu memenuhi jumlah pesanan dari konsumen.

Menurut Charles Jhony Mantho Sianturi, Elsi Ardini, dan Nita Sari Br Sembiring dalam jurnalnya dijelaskan bahwa Prediksi (forecasting) prediksi apa yang akan terjadi pada waktu yang akan datang, sedang rencana, merupakan penentuan apa yang akan dilakukan pada waktu yang akan dilakukan. Prediksi dilakukan hampir semua orang baik itu pemerintah pengusaham maupun orang awam [1].

Didalam penelitian Ernita Silitonga, Fujiati. Yanuar Adi Kurniawan menjelaskan bahwa Peramalan adalah proses menaksirkan/ memperkirakan sesuatu di masa yang akan dating yang berdasarkan pada data yang ada di masa lalu yang kemudian dianalisis secara ilmiah dengan memakai metode statistika dengan tujuan supaya memperbaiki peristiwa yang akan terjadi di waktu yang akan datang. Tujuan diadakannya peramalan atau forecasting adalah untuk meminimalisasi resiko serta faktor ketidak pastian. Dengan adanya hasil peramalan, diharapkan tindakan atau keputusan dari suatu perusahaan atau organisasi dapat memberi dampak lebih baik pada jangka yang akan datang [2].

Sedangkan menurut penelitian Mhd. Ridwansyah, Fhery Agustin dan Ria Eka Sari, dapat disimpulkan bahwa dengan Sistem Peramalan penjualan yang berguna bagi CEO dalam menentukan jumlah produksi produk sehingga mengantisipasi agar tidak terjadi PO yang dapat membuat omset Perusahaan menurun [3].

Salah satu metode peramalan yang dapat diterapkan adalah metode single moving average, sebab metode ini digunakan untuk meramalkan sesuatu yang tidak musiman. Kartu perdana internet dan voucher paket data bukan merupakan suatu barang yang hanya laku pada musim tertentu, melainkan selalu ada penjualan dan peminat disetiap musim.

Menurut Yuharuddin didalam penelitiannya menjelaskan bahwa Metode single moving average merupakan bagian dari metode moving average. Metode moving average (rata-rata bergerak) sendiri memiliki makna suatu metode peramalan yang menggunakan data-data permintaan dalam beberapa periode dimasa lampau secara berurutan, biasanya mencakup dua belas bulan. Data permintaan ini dihaluskan (smoothed out) dengan cara membagi jumlah permintaan selama beberapa periode dengan jumlah periode sehingga ditemukan jumlah rata-rata permintaan per periode [4]. 


\section{METODE PENELITIAN}

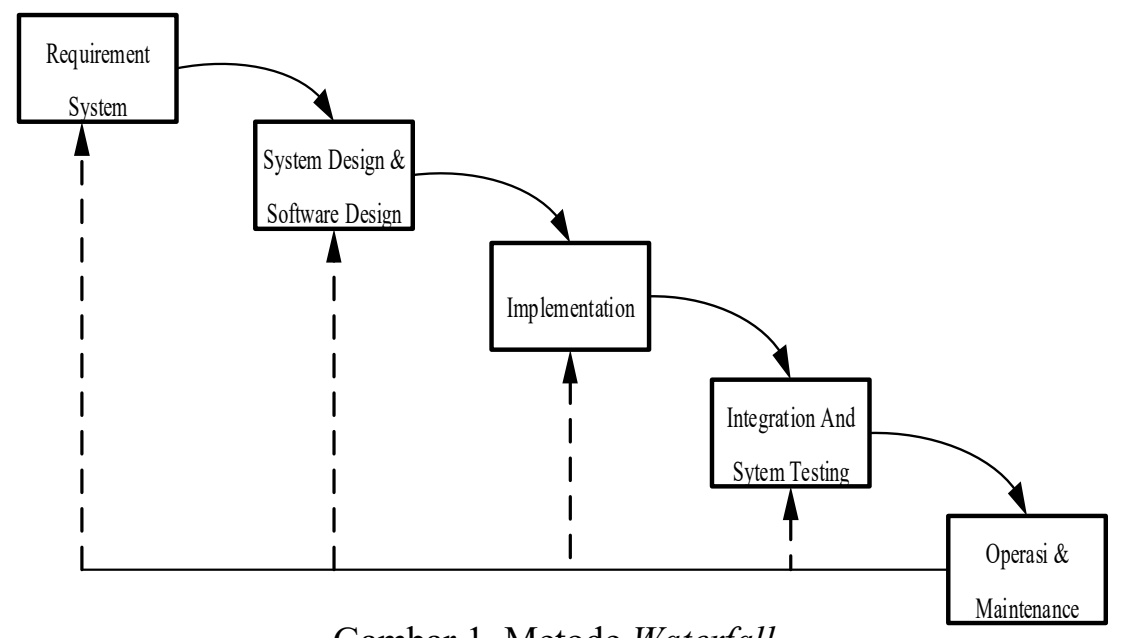

Gambar 1. Metode Waterfall

1. Requirement System, pada tahap ini pengumpulan kebutuhan sistem secara lengkap dilakukan untuk kemudian dianalisis dan dilakukan pendefinisian terhadap kebutuhan yang harus dipenuhi oleh aplikasi yang hendak dibangun. Adapun hal-hal yang harus dipenuhi oleh aplikasi yaitu memiliki kemampuan dalam memberikan informasi kepada pengambil keputusan untuk menentukan jumlah stok kartu perdana internet dan voucher paket data yang perlu disediakan.

2. System Design dan Software Design, pada tahap ini akan dilakukan proses perancangan terhadap tampilan aplikasi atau sistem informasi, user interface yang user friendly sehingga mudah dimengerti, pada tahap inilah kebutuhan database dipenuhi.

3. Implementation, tahap ini merupakan tahapan dimana sistem informasi telah selesai dirancang dan siap untuk di install pada sebuah sistem (server) baik database maupun aplikasi. Pada tahap inilah metode single moving average diterapkan dalam aplikasi yang dibangun.

4. Integration \& System Testing, ditahap ini proses ujicoba terhadap aplikasi yang telah selesai dirancang dilakukan, pengujian ini perlu dilaksanakan untuk mengetahui apakah aplikasi sudah berjalan sesuai dengan alur kerja yang telah ditetapkan ataukah masih terdapat kesalahan-kesalahan yang perlu diperbaiki agar hasil tujuan pembangunan aplikasi tercapai.

5. Operation \& Maintenance, Tahapan ini adalah tahap terakhir dari seluruh rangkaian kegiatan perancangan aplikasi, dimana pada tahap ini aplikasi dianggap sudah selesai secara keseluruhan dan sudah dapat beroperasi dengan baik.

\section{HASIL DAN PEMBAHASAN}

\subsection{Penerapan Metode Single Moving Average}

Pada penelitian ini penulis menggunakan metode Single Moving Average, berikut adalah penjabaran dari metode penelitianya. 


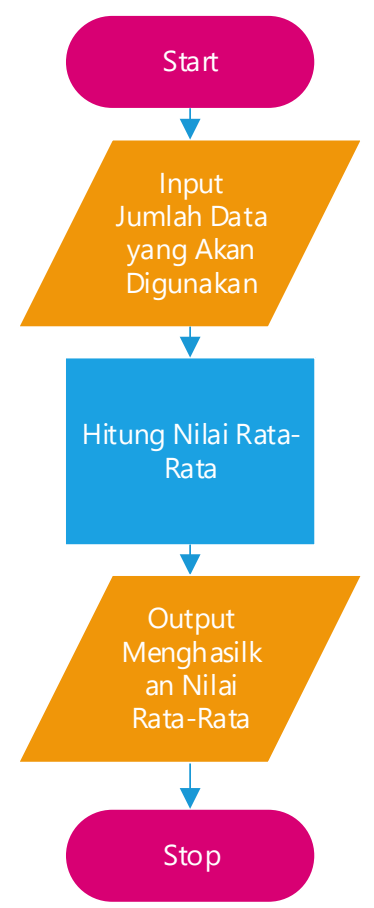

Gambar 2. Flowchart Metode Single Moving Average

Langkah-langkah penelitian menggunakan Metode Single Moving Average adalah :

Contoh Kasus :

Hitunglah prediksi penjualan sampel kartu perdana internet dan voucher paket data pada bulan Juli 2020 menggunakan metode single moving average dimana data penjualan Toko Karya Pulsa pada tahun 2019 dapat dilihat pada tabel berikut.

Tabel 1. Data Penjualan Toko Karya Pulsa

\begin{tabular}{|c|c|c|c|c|c|c|c|c|c|c|c|c|c|}
\hline \multirow{2}{*}{ No. } & \multirow{2}{*}{ Nama Barang } & \multicolumn{12}{|c|}{ Jumlah Terjual } \\
\hline & & Jul & Agu & Sep & Okt & Nov & Des & Jan & Feb & Mar & Apr & Mei & Jun \\
\hline 1. & Telkomsel 10 GB & 45 & 38 & 23 & 18 & 30 & 36 & 52 & 40 & 54 & 62 & 30 & 25 \\
\hline 2. & XL 8 GB & 173 & 162 & 17 & 15 & 22 & 9 & 13 & 11 & 20 & 14 & 28 & 26 \\
\hline 3. & Axis $3 \mathrm{~GB}$ & 11 & 9 & 13 & 10 & 12 & 8 & 14 & 12 & 13 & 16 & 12 & 10 \\
\hline 4. & Voucher Axis $5 \mathrm{~GB}$ & 98 & 106 & 99 & 110 & 107 & 100 & 96 & 102 & 98 & 94 & 110 & 125 \\
\hline 5. & IM3 4 GB & 21 & 8 & 4 & 6 & 11 & 7 & 9 & 13 & 15 & 18 & 3 & 8 \\
\hline 6. & Voucher IM3 3 Unli & 1 & 10 & 10 & 14 & 16 & 11 & 13 & 2 & 9 & 12 & 16 & 13 \\
\hline 7. & Smartfren 10 GB & 31 & 28 & 24 & 26 & 30 & 22 & 19 & 23 & 22 & 20 & 32 & 35 \\
\hline 8. & Voucher Sms & 1 & 0 & 0 & 105 & 78 & 80 & 63 & 78 & 76 & 80 & 85 & 73 \\
\hline 9. & Tri 6 GB & 80 & 80 & 46 & 65 & 78 & 90 & 88 & 55 & 68 & 79 & 83 & 76 \\
\hline 10. & Voucher Tri 1.5 GB & 10 & 12 & 14 & 170 & 136 & 128 & 150 & 171 & 101 & 124 & 139 & 146 \\
\hline
\end{tabular}

1. Menentukan jumlah data yang akan digunakan dalam melakukan peramalan penjualan menggunakan metode single moving average. Pada tabel sudah disediakan data penjualan dua belas bulan terakhir, maka data yang akan digunakan untuk menghitung prediksi penjualan adalah data penjualan dua belas bulan tersebut.

2. Menghitung nilai rata-rata dengan menggunakan rumus peramalan dengan metode single moving average.

a. Prediksi penjualan kartu perdana internet Telkomsel 10 GB pada bulan Juli 2020.

$$
\begin{aligned}
& \boldsymbol{F}_{\boldsymbol{t}+\mathbf{1}}=\frac{\boldsymbol{X}_{1+} \boldsymbol{X}_{2+\cdots+} \boldsymbol{X} \boldsymbol{n}}{\boldsymbol{N}} \\
& \boldsymbol{F}_{\boldsymbol{t}+\mathbf{1}}=45+38+23+18+30+36+52+40+54+62+30+25
\end{aligned}
$$




$$
\boldsymbol{F}_{t+1}=37,75 \mathrm{pcs}
$$

b. Prediksi penjualan kartu perdana internet XL 8 GB pada bulan Juli 2020.

$$
\begin{aligned}
& \boldsymbol{F}_{\boldsymbol{t}+\mathbf{1}}=\frac{\boldsymbol{X}_{\mathbf{1}+} \boldsymbol{X}_{2+\ldots+} \boldsymbol{X} \boldsymbol{n}}{\boldsymbol{N}} \\
& \boldsymbol{F}_{\boldsymbol{t}+\mathbf{1}}=\frac{173+162+17+15+22+9+13+11+20+14+28+26}{12} \\
& \boldsymbol{F}_{\boldsymbol{t + 1}}=42,5 \mathrm{pcs}
\end{aligned}
$$

c. Prediksi penjualan kartu perdana internet Axis 3 GB pada bulan Juli 2020.

$$
\begin{aligned}
& \boldsymbol{F}_{\boldsymbol{t}+\mathbf{1}}=\frac{\boldsymbol{X}_{1+} \boldsymbol{X}_{2+\cdots+} \boldsymbol{X} \boldsymbol{n}}{\boldsymbol{N}} \\
& \boldsymbol{F}_{\boldsymbol{t}+\mathbf{1}}=\frac{11+9+13+10+12+8+14+12+13+16+12+10}{12} \\
& \boldsymbol{F}_{\boldsymbol{t}+\mathbf{1}}=11,67 \mathrm{pcs}
\end{aligned}
$$

d. Prediksi penjualan voucher paket data Axis 5 GB pada bulan Juli 2020.

$$
\begin{aligned}
\boldsymbol{F}_{\boldsymbol{t}+\mathbf{1}} & =\frac{\boldsymbol{X}_{1+} \boldsymbol{X}_{2+\ldots+} \boldsymbol{X} \boldsymbol{n}}{\boldsymbol{N}} \\
\boldsymbol{F}_{\boldsymbol{t}+\mathbf{1}} & =\frac{98+106+99+110+107+100+96+102+98+94+110+125}{12} \\
\boldsymbol{F}_{\boldsymbol{t}+\mathbf{1}} & =103,75 \mathrm{pcs}
\end{aligned}
$$

e. Prediksi penjualan kartu perdana internet IM3 4 GB pada bulan Juli 2020.

$$
\begin{aligned}
& \boldsymbol{F}_{\boldsymbol{t}+\mathbf{1}}=\frac{\boldsymbol{X}_{\mathbf{1}+\boldsymbol{X}_{2+\cdots+} \boldsymbol{X} \boldsymbol{n}}}{\boldsymbol{N}} \\
& \boldsymbol{F}_{\boldsymbol{t}+\mathbf{1}}=\frac{21+8+4+6+11+7+9+13+15+18+3+8}{12} \\
& \boldsymbol{F}_{\boldsymbol{t}+\mathbf{1}}=10,25 \mathrm{pcs}
\end{aligned}
$$

f. Prediksi penjualan voucher paket data IM3 3GB Unlimited pada bulan Juli 2020.

$$
\begin{aligned}
& \boldsymbol{F}_{\boldsymbol{t}+\mathbf{1}}=\frac{\boldsymbol{X}_{\mathbf{1}+} \boldsymbol{X}_{2+\ldots+} \boldsymbol{X} \boldsymbol{n}}{\boldsymbol{N}} \\
& \boldsymbol{F}_{\boldsymbol{t}+\mathbf{1}}=\frac{1}{\mathbf{1 2}}(1+10+10+14+16+11+13+2+9+12+16+13) \\
& \boldsymbol{F}_{\boldsymbol{t}+\mathbf{1}}=10,58 \mathrm{pcs}
\end{aligned}
$$

g. Prediksi penjualan kartu perdana internet Smartfren 10 GB pada bulan Juli 2020.

$$
\begin{aligned}
& \boldsymbol{F}_{\boldsymbol{t}+\mathbf{1}}=\frac{\boldsymbol{X}_{\mathbf{1}+\boldsymbol{X}_{2+\ldots+} \boldsymbol{X} \boldsymbol{n}}}{\boldsymbol{N}} \\
& \boldsymbol{F}_{\boldsymbol{t}+\mathbf{1}}=\frac{31+28+24+26+30+22+19+23+22+20+32+35}{12} \\
& \boldsymbol{F}_{\boldsymbol{t}+\mathbf{1}}=26 \mathrm{pcs}
\end{aligned}
$$

h. Prediksi penjualan voucher paket data Smartfren Unlimited pada bulan Juli 2020.

$$
\begin{aligned}
& \boldsymbol{F}_{\boldsymbol{t}+\mathbf{1}}=\frac{\boldsymbol{X}_{\mathbf{1}+\boldsymbol{X}_{2+\cdots+} \boldsymbol{X} \boldsymbol{n}}}{\boldsymbol{N}} \\
& \boldsymbol{F}_{\boldsymbol{t}+\mathbf{1}}=\frac{1+0+0+105+75+80+63+78+76+80+85+73}{12} \\
& \boldsymbol{F}_{\boldsymbol{t + 1}}=59,67 \mathrm{pcs}
\end{aligned}
$$

i. Prediksi penjualan kartu perdana internet Tri 6 GB pada bulan Juli 2020 .

$$
F_{t+1}=\frac{X_{1+} X_{2+\cdots+} X n}{N}
$$




$$
\begin{aligned}
& \boldsymbol{F}_{\boldsymbol{t}+\mathbf{1}}=\frac{1}{12}(80+80+46+65+78+90+88+55+68+79+83+76) \\
& \boldsymbol{F}_{\boldsymbol{t}+\mathbf{1}}=74 \mathrm{pcs}
\end{aligned}
$$

j. Prediksi penjualan voucher paket data Tri 1.5 GB pada bulan Juli 2020.

$$
\begin{aligned}
& \boldsymbol{F}_{\boldsymbol{t}+\mathbf{1}}=\frac{\boldsymbol{X}_{\mathbf{1}+} \boldsymbol{X}_{2+\ldots+} \boldsymbol{X} \boldsymbol{n}}{\boldsymbol{N}} \\
& \boldsymbol{F}_{\boldsymbol{t}+\mathbf{1}}=\frac{10+12+14+170+136+128+150+171+101+124+139+146}{12} \\
& \boldsymbol{F}_{\boldsymbol{t}+\mathbf{1}}=108,41 \mathrm{pcs}
\end{aligned}
$$

Adapun tabel dari hasil peramalan dapat dilihat pada tabel III.2 berikut ini:

Tabel 2. Tabel Hasil Peramalan Menggunakan Metode Single Moving Average

\begin{tabular}{|c|l|c|}
\hline No. & \multicolumn{1}{|c|}{ Nama Barang } & Hasil Peramalan \\
\hline 1. & Telkomsel 10 GB & 37,75 \\
\hline 2. & XL 8 GB & 42,5 \\
\hline 3. & Axis 3 GB & 11,67 \\
\hline 4. & Voucher Axis 5 GB & 103,75 \\
\hline 5. & IM3 4 GB & 10,25 \\
\hline 6. & Voucher IM3 3 Unli & 10,58 \\
\hline 7. & Smartfren 10 GB & 26 \\
\hline 8. & Voucher Smartfren Unli & 59,67 \\
\hline 9. & Tri 6 GB & 74 \\
\hline 10. & Voucher Tri 1.5 GB & 108,41 \\
\hline
\end{tabular}

\subsection{Perancangan Sistem}

\section{Use Case Diagram}

Use Case merupakan pemodelan dan menunjukkan actor dan kelakuan sistem. Use Case juga menjelaskan urutan kegiatan yang dilakukan actor. Sebuah use case menampilkan interaksi antar actor dengan sistem. Berikut adalah use case diagram peramalan penjualan kartu perdana internet dan voucher paket data pada Toko Karya Pulsa dapat dilihat pada gambar 3 berikut.

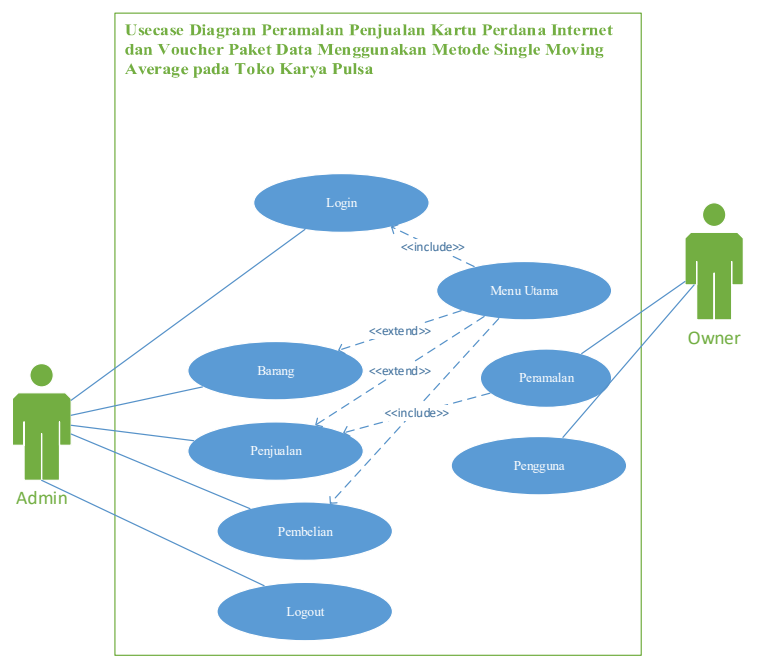

Gambar 3. Use Case Diagram

\subsection{Tampilan Hasil}

Berdasarkan hasil dari pembuatan aplikasi yang telah dibuat maka dihasilkan dalam bagianbagian yang ditampilkan dalam bentuk form input dan output. Berikut ini adalah beberapa tampilan dan program aplikasi yang telah dibuat. 
1. Desain Form Login

Desain form login dapat dilihat di gambar 4 sebagai berikut :

Sign In

\begin{tabular}{|l|}
\hline Username \\
\hline Password \\
\hline \\
Login
\end{tabular}

Gambar 4. Desain Form Login

2. Desain Form Menu Utama

Desain form menu utama dapat dilihat pada gambar 5 sebagai berikut:

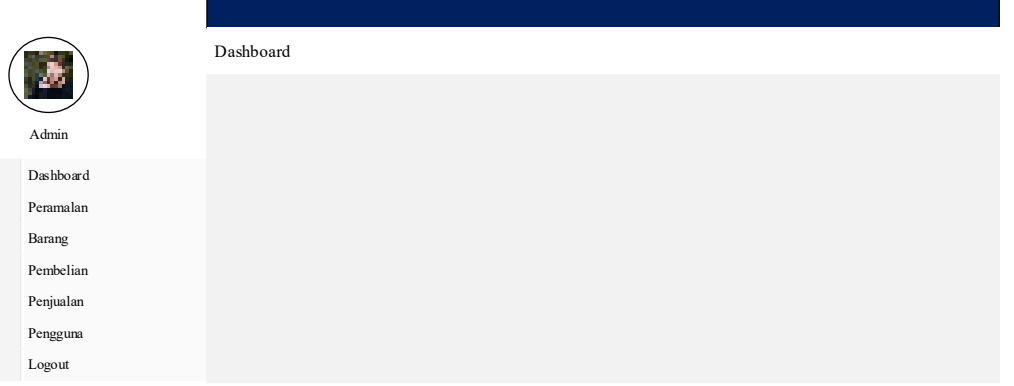

Gambar 5. Desain Form Menu Utama

3. Desain Form Peramalan

Desain form peramalan dapat dilihat pada gambar 6 sebagai berikut :

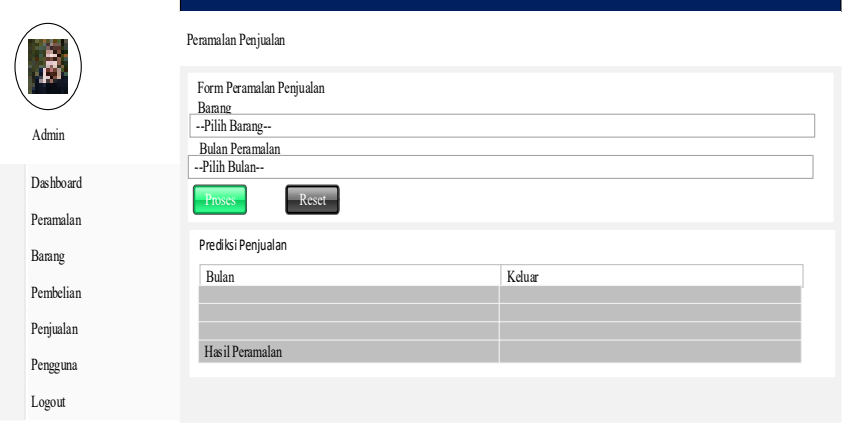

Gambar 6. Desain Form Peramalan

4. Desain Form Data Barang

Desain form data barang dapat dilihat pada gambar 7 sebagai berikut :
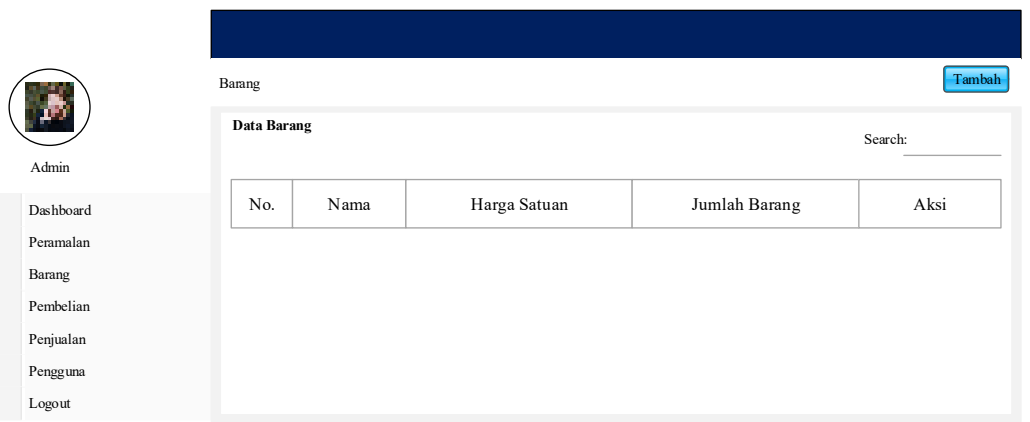

Gambar 7. Desain Form Data Barang 
5. Desain Form Tambah Barang

Desain form tambah barang dapat dilihat pada gambar 8 sebagai berikut :
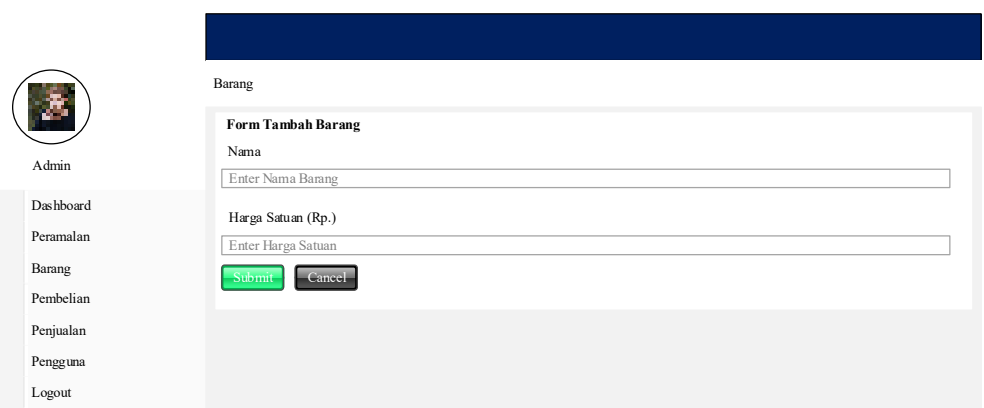

Gambar 8. Desain Form Tambah Barang

6. Desain Form Edit Barang

Desain form edit barang dapat dilihat pada gambar 9 sebagai berikut :
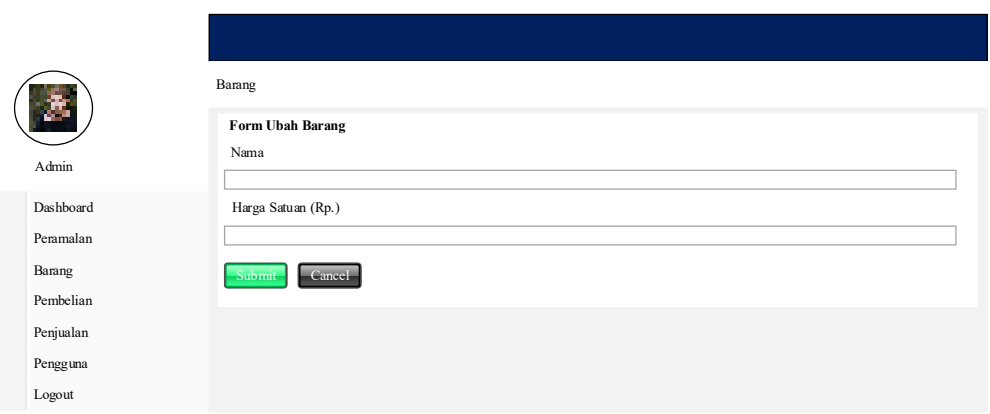

Gambar 9. Desain Form Edit Barang

7. Desain Form Pembelian

Desain form pembelian dapat dilihat pada gambar 10 sebagai berikut :
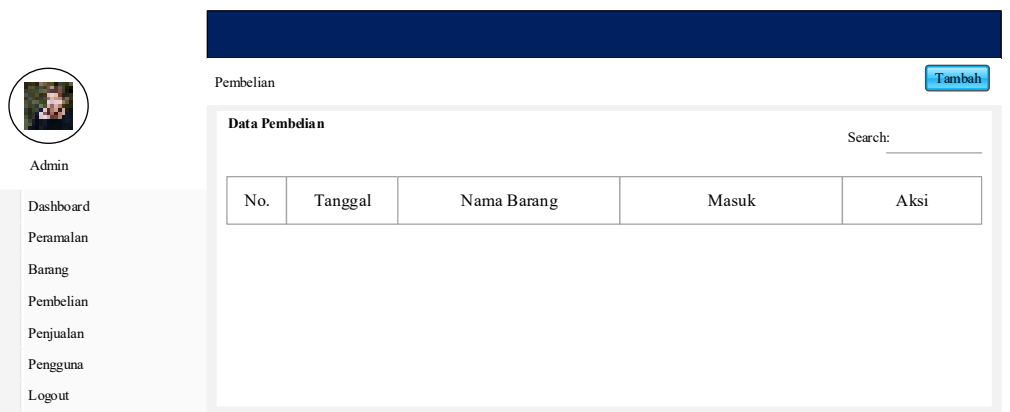

Gambar 10. Desain Form Pembelian

8. Desain Form Tambah Pembelian

Desain form pembelian dapat dilihat pada gambar 11 sebagai berikut :
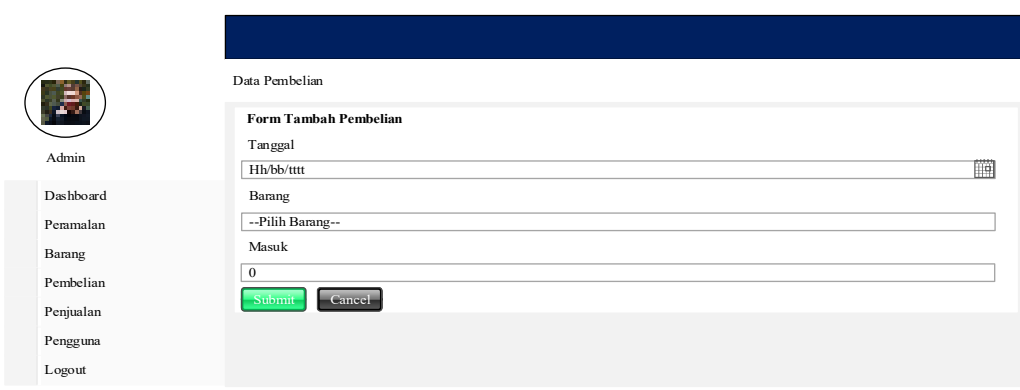

Gambar 11. Desain Form Tambah Pembelian 
9. Desain Form Edit Pembelian

Desain form pembelian dapat dilihat pada gambar 12 sebagai berikut :
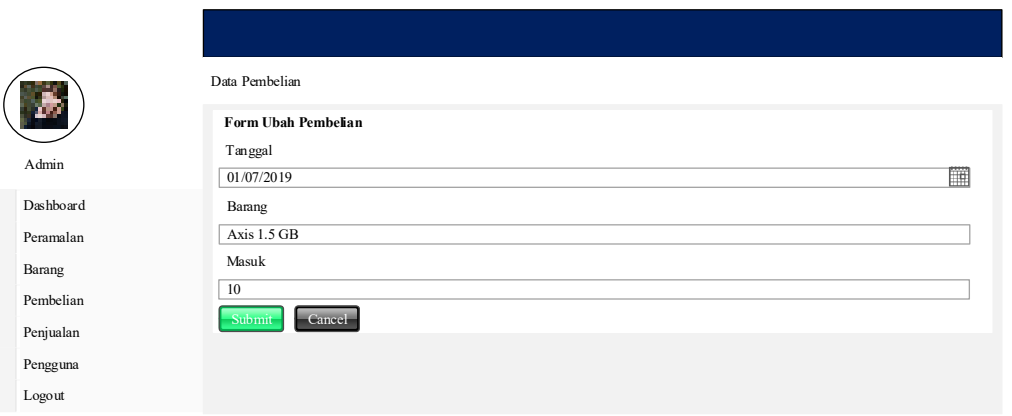

\section{Gambar 12. Desain Form Edit Pembelian}

10. Desain Form Penjualan

Desain form pembelian dapat dilihat pada gambar 13 sebagai berikut :
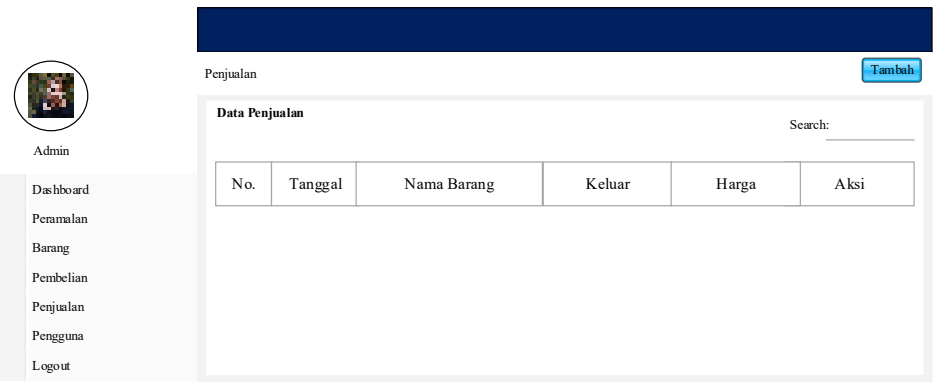

Gambar 13. Desain Form Penjualan

11. Desain Form Tambah Penjualan

Desain form tambah penjualan dapat dilihat pada gambar 14 sebagai berikut :
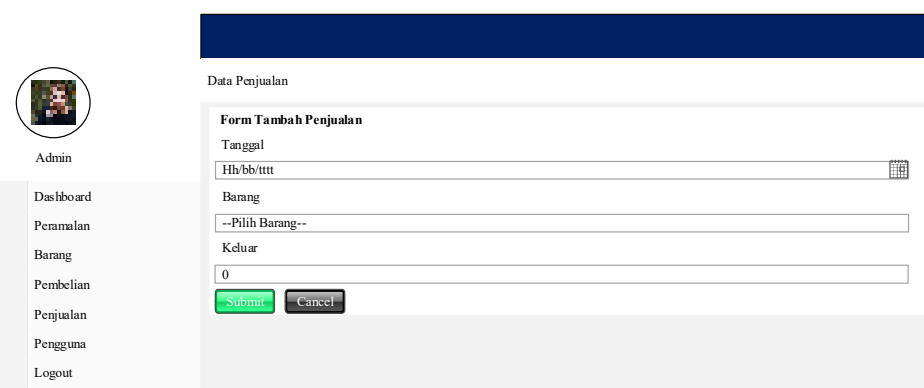

Gambar 14. Desain Form Tambah Penjualan

12. Desain Form Edit Penjualan

Desain form edit penjualan dapat dilihat pada gambar 15 sebagai berikut :
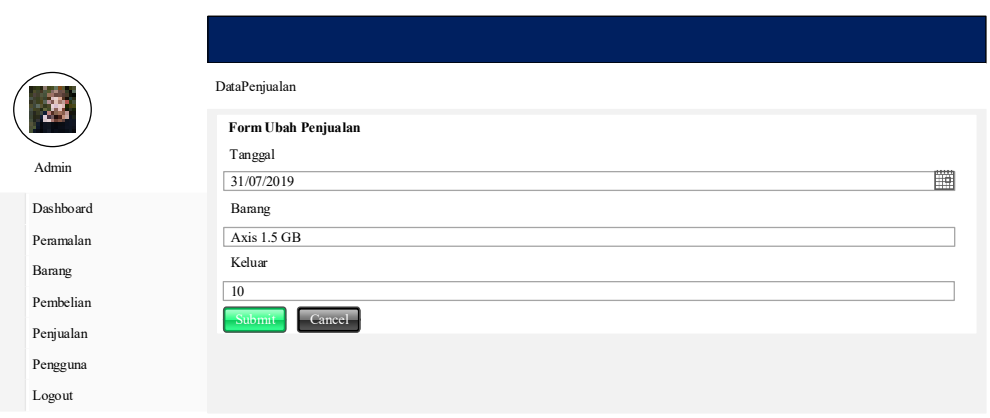

Gambar 15. Desain Form Edit Penjualan 
13. Desain Form Pengguna

Desain form pengguna dapat dilihat pada gambar 16 sebagai berikut :
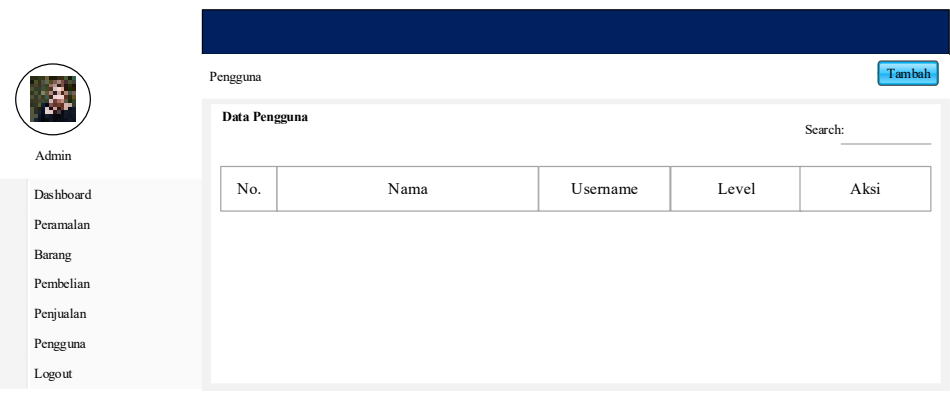

Gambar 16. Desain Form Pengguna

14. Desain Form Tambah Pengguna

Desain form tambah pengguna dapat dilihat pada gambar 17 sebagai berikut :

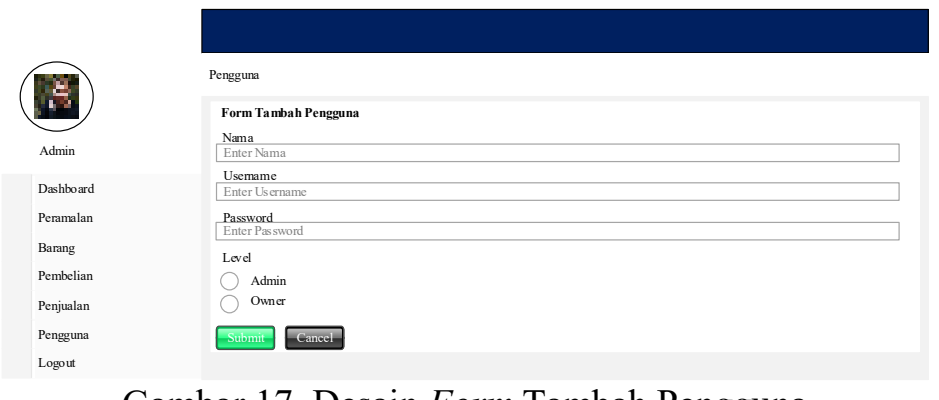

Gambar 17. Desain Form Tambah Pengguna

15. Desain Form Edit Pengguna

Desain form edit pengguna dapat dilihat pada gambar 18 sebagai berikut :

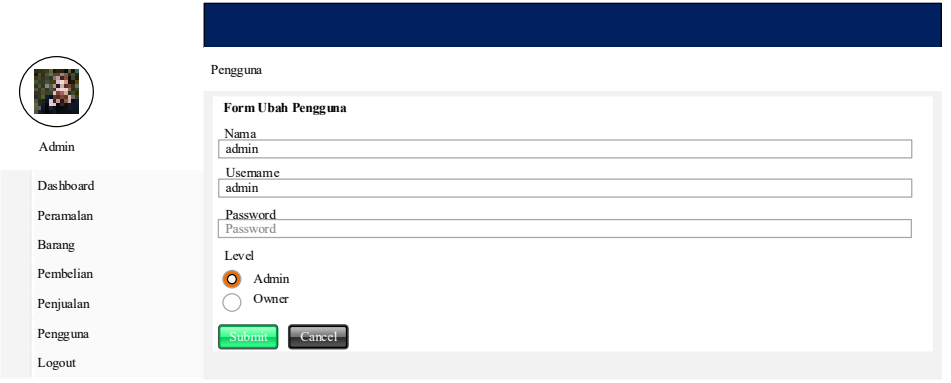

Gambar 18. Desain Form Edit Pengguna

\section{KESIMPULAN}

Berdasarkan proses penelitian yang penulis lalui dan dengan terselesaikannya aplikasi peramalan penjualan kartu perdana internet dan voucher paket data menggunakan metode single moving average pada Toko Karya Pulsa maka diperoleh beberapa keseimpulan sebagaimana penulis sampaikan berikut ini:

1. Aplikasi peramalan penjualan kartu perdana internet dan voucher paket data yang penulis bangun dapat memberikan kemudahan dalam menyimpan dan mengelola data barang, data penjualan, dan data pembelian di Toko Karya Pulsa.

2. Terciptanya sebuah aplikasi berbasis website yang dapat membantu mengurangi kemungkinan kesalahan dalam menetapkan jumlah barang yang harus disediakan oleh pemilik Toko Karya Pulsa agar permintaan konsumen dapat terpenuhi dengan baik tanpa harus kuota internet yang hangus. 
3. Prediksi dilakukan dengan menerapkan metode single moving average dimana metode ini memperhitungkan data penjualan dimasa lampau untuk dijadikan acuan perhitungan jumlah kemungkinan penjualan dimasa mendatang.

\section{SARAN} berikut:

Beberapa saran dari penulis untuk pengembangan aplikasi yang telah dibangun yakni sebagai

1. Seiring dengan berkembangnya kebutuhan pengguna akan spesifikasi sistem hendaknya aplikasi ini juga nantinya bisa mengikuti kebutuhan tersebut dengan menambahkan fitur-fitur yang bermanfaat bagi pemenuhan kebutuhan pengguna.

2. Untuk mengantisipasi kemungkinan aplikasi tidak dapat diakses oleh pengguna akibat lupa password kiranya fitur lupa password dapat ditambahkan kedepannya.

\section{UCAPAN TERIMA KASIH}

Penulis mengucapkan terima kasih yang sebesar-besarnya kepada Universitas Potensi Utama dan pembimbingnya yang telah mengajarkan banyak ilmu dan tata cara penulisan laporan penelitian ini dengan baik dan benar.

\section{DAFTAR PUSTAKA}

[1] Sianturi, C. J. M., Ardini, E., \& Sembiring, N. S. B. (2020). Sales Forecasting Information System Using the Least Square Method in Windi Mebel. Jurnal Inovasi Penelitian, 1(2), 7582.

[2] Silitonga, E., \& Fujiati, F. (2019). Penerapan Metode Single Exponential Smoothing Pada Penentuan Penjualan Karton Jadi Pada PT. Industri Pembungkus International. IT (INFORMATIC TECHNIQUE) JOURNAL, 7(1), 36-48.

[3] Ridwansyah, M., Agustin, F., \& Sari, R. E. (2018). Aplikasi E-Commerce Produk Kecantikan Import Dilengkapi Dengan Sistem Informasi Sales Forecasting Menggunakan Metode Trend Moment Pada PT. Ouzen Anugerah Indonesia. IT (INFORMATIC TECHNIQUE) JOURNAL, 6(1), 36-45.

[4] Yudaruddin, R. (2019). Forecasting untuk Kegiatan Ekonomi dan Bisnis. RV Pustaka Horizon. 